\title{
THE DE MESTRAL PROJECT: USING MACRO PHOTO-JOURNALING TO STIMULATE INTEREST IN BIO-INSPIRED DESIGN AND SCIENCE, TECHNOLOGY, ENGINEERING AND MATHEMATICS DISCIPLINES
}

\author{
BROOK S. KENNEDY \\ Virginia Polytechnic Institute and State University.
}

\begin{abstract}
Bio-inspired design (BID) and its many variants (biomimetics, biomimicry etc.) continues to be a promising innovation methodology in which practitioners from industry and academia search nature's evolutionary diversity for meaningful design opportunities. However, despite BID's potential to contribute greater value to society, it remains an obscure field. In this paper, we present a case demonstrating how a novel educational exercise could play an important role in advancing the field by stimulating student interest in BID and the more broadly associated Science Technology, Engineering and Mathematics (STEM) fields which drive it. Specifically, we discuss a cross-disciplinary university seminar that uses an experimental photo journaling exercise called the "de Mestral Project" which aims to recreate the successful invention process of Velcro by Engineer Georges de Mestral. This exercise cultivates observation skills, or the ability to look closer at the natural world as a foundation for uncovering new opportunities for design. Critical to the activity is the use of macro photography to help facilitate this discovery process. The outcome of this project has led to early stage BID concepts that have been explored more deeply in subsequent funded research efforts and in capstone Industrial Design studio projects. The development of the de Mestral project in ongoing; the purpose of this paper is to describe its methods and preliminary outcomes.

Keywords: bio-inspiration, bio-inspired design, biomimicry, biomimetics, interdisciplinary collaboration, innovation, sustainable design, STEM.
\end{abstract}

\section{INTRODUCTION}

In the past decade, many studies have emphasized the importance of Science Technology, Engineering and Mathematics (STEM) graduates in building and maintaining an innovation economy, yet performance and enrollments in these disciplines especially in the USA have fallen behind Asian and European Universities [1, 2]. Much effort has been invested to increase enrollments to meet the needs of industry and to help solve the grand challenges humankind faces in the 21 st century [3, 4]. Bio-inspired design (BID) in particular, as a STEM-driven line of research, has shown broad potential to drive solutions that impact society and economic development. Especially as global demand grows for sustainable products and better resource management, namely increasing access to clean water, natural examples will continue to drive innovation in these areas (renewable materials, water purification, hydrophobic surfaces, desalination, fog water capture among others). Still, many practitioners continue to wonder how to better harvest BID opportunities beginning with basic scientific research through commercialization. Explanations for BID's slow acceptance have been 
attributed to many factors: complexity of the process, challenges to industrially reproducing nature's small scale design features (Lotusan, 3d printed Shark Skin at the Wyss Institute) [5], lack of recognition for success stories (PureBond) [6], skepticism in the practice and lack of investment options amongst others. More recent economic forecasts suggest that BID activity has great potential to increase dramatically [7]. Earlier in the innovation pipeline at research universities, BID continues to grow in significance measured by a steadily rising rate of published papers on BID topics [8]. Research centers engaged in studying Biology with a lens toward translation to technical applications continue to emerge. At the author's University, Virginia Tech, life science and engineering labs under the VTBIST (Virginia Tech Bio-Inspired Science and Technology) center continue to expand in numbers. Notable examples include labs studying particularly extreme phenomenon in remarkable species; biosonar systems in bats, biomechanics in flying snakes, desalination abilities of mangrove trees and many others. Universities worldwide are engaged in studying nature with similar interest in design application potential.

To accelerate the BID's impact, one major opportunity lies in increasing interest and awareness of BID at a younger age. This paper will discuss how the ongoing pilot of the de Mestral Project, an educational tool aimed at immersing students in the promise of BID can contribute to this challenging effort. By tasking students to explore and reflect on extreme organisms and mundane natural phenomenon in their own back yards, students are exposed to exciting possibilities for deeper basic research and potential opportunities for innovation. Engineer George de Mestral, after whom the project is named, developed Velcro in a similar manner by closely observing the unique connective hooks of burdock seeds, which is now a global billion-dollar industry [9].

\section{THE DE MESTRAL PROJECT: PEDAGOGICAL CONTEXT AND GOALS}

The de Mestral journaling project was introduced in an honors interdisciplinary BID seminar developed at Virginia Tech in 2014 called "Integrating Biology, Design and Engineering" and then expanded in 2015 [10]. Course development in this area is becoming more common in design and engineering programs globally, especially in the United States, and has been integrated at the module, project, course and program levels. BID concepts and examples have been used by several institutions to educate students about design innovation, using nature as another source of design inspiration, and for integrating concepts of sustainability into design curricula. Probably the most well-known US institution with course work in BID is Georgia Tech, which offers multiple interdisciplinary classes and a certificate through the Center for Biologically Inspired Design [11]. Arizona State University likewise has graduate courses teaching associated themes in Biomimicry [12].

Similar in content to these classes, the Virginia Tech seminar "Integrating Biology Design and Engineering" was offered by professors in Industrial Design, Mechanical Engineering and Biological Sciences in the Spring of 2014 with roughly 16 undergraduate students majoring equally in these discipline areas. The course consisted of initial lectures and readings in the background and theory of Bio-inspiration including widely known examples of products or services that were in the process of or had already been commercialized.

\section{1 "Solution-based" design exercises}

The seminar met for 3 hours of class time per week over the course of a 15-week semester. In the second class, students were challenged with a short in-class "Solution-based" warm up 
design project, where they could select organisms with extreme evolutionary traits from a pile of picture cards where the description of the extreme trait was summarized on the back side [13]. Examples included Barrel Cacti, Puffer fish, Pinecones, Geckos, Fireflies among many others. From these predefined functional traits, students were able to research further in textbooks or online and then verbally or visually brainstorm possible conceptual application opportunities translated from these phenomena. The deliverable for the exercise was a group share-out and quick description of their proposed conceptual design. This exercise provided an easy introduction to the thought processes and mindset of BID and paved the way for the de Mestral journaling pilot, which was also driven by Solution-based BID. Beginning in week 2 of the class, students were asked to keep a journal of Biological artifacts they would see outside. Despite the winter cold, Virginia Tech is situated in a remote rural area of the Blue Ridge mountains in the eastern USA where national parks and nature trails are abundant. Students were given macro lenses designed for their smart phones and were asked to submit a journal entry every week consisting of a picture of a biological artifact and a zoomed in view of an intriguing detail. They were then asked to comment verbally or visually water how what they saw could inform some kind of practical application. In addition to being enjoyable and popular, this exercise created a common interdisciplinary language of BID inquiry that kept students engaged and asking questions throughout the term. The project was not graded but was enthusiastically completed by every student.

\section{2 "Problem-based" term project}

In parallel with the de Mestral project, the remainder of the term focused on a main "Problem-based" team design project wherein they were given a selection of broad problem areas that they were asked to narrow and solve using Biological analogs to inform them. This project was the principal deliverable for their class grade. The teams consisted of students representing Design, Engineering and Biology fields. The challenge topics available for teams to choose from included:

1. Water stewardship: How can Biology inform better water management approaches?

2. Biomimicry Institute Transportation Challenge: How can Biology inform better approaches and strategies for human transportation?

3. Define your own challenge: How can Biology inform alternative and better approaches to solving known wicked problems?

Project topics were evenly spread across the class teams ensuring that one team addressed each challenge topic. Notwithstanding, of the teams two (2) chose water stewardship, one (1) chose the transportation challenge and one (1) chose their own (which ended up being about water anyway).

\subsection{Challenges with problem-based BID}

While it is an absolutely worthwhile task to challenge students to address big global problems, this project presented many difficulties. One of the central problems arose in the ability of students to find suitable biological benchmarks from which to inform and drive their design ideation. Yen et al. who have defined the "Problem vs. Solution-based" terms have written at length about the inherent difficulties of this method. Problem-based BID is the 
most challenging because it relies on networks of biological knowledge and expertise to support the design process. In essence, once a good problem is defined, which is no trivial task in its own right, difficulties arise then in finding a breadth of suitable biological solutions that are relevant to helping inform solutions to their problem.

Problem-Based: In the face of global water shortages, how can nature inspire strategies to collect water?

Solution-Based: Sequoia Sempervirens branch needles extract water from fog in a process known as fog drip. How do they do it and how could we replicate it to provide drinkable water in arid areas of the globe?

In many cases of Problem-based BID projects, the student teams ended up focusing on the same sets known of Biological phenomenon for solutions (Lotus Leaves, Namib Beetle etc.). As such, there was a lot of repetition in the solution directions that are published in BID competitions. Our class had a such an experience in Spring 2014: one team chose water stewardship as a project and then focused on finding less toxic ways of preventing ice on campus pedestrian paths to avoid injurious falls. In the end, beyond finding an arctic fish species that led to a proposal for a benign ice retardant spray, the team fell back on the Lotus leaf. By the end of the project they proposed Lotus leaf-inspired path surfaces with the ability through micro surface textures to inhibit frost and ice. This solution was driven through the Biomimicry Institute's AskNature.org database which at the time was probably the best available online tool to help the teams find biological solution areas to their problems [14]. Another alternative was to find faculty members in these specialized areas on demand, but this proved impractical even with a Biology faculty member in the class to act as an ambassador. It is never known which faculty would be helpful to student projects ahead of time to plan for their formal class participation. When we found appropriate faculty during the class who might be able to help the projects, they did not have the availability to help in the middle of the term. In the future, we will narrow in on challenge topics in specific areas where we can engage Biology faculty in the relevant areas ahead of time. Such relevant resources are critical to interpret biological phenomenon in terms of function and thereby develop solutions. Otherwise, student teams chose problems based on the availability of knowledge to help them solve their challenge.

Moreover, in the absence of a good Biological means of solving their problem, one team came up with a more plausible non-biological means of doing so and were disappointed that they could not simply pursue this direction. They were passionate about their solution but felt they had to compromise to fulfill their BID project brief. By the end, they settled on the first biological analog they could find to solve their problem even though it was less effective and compelling.

\subsection{Accessibility of solution-based BID}

By the end of the Spring 2014 class, it was no surprise that feedback suggested students found Solution-based BID, notably the journal and warm up exercise more accessible than the "Problem-based" method and the quality of the work showed. This is not to suggest that Problem-based projects should be abandoned in undergraduate curriculums. It is merely to say that improving access to Biological information is critical to improve design outcomes in "Problem-based" BID projects. As a result, we resolved to increase the role of "Solution-based" BID in the following Spring 2015 because of its comparative success in student engaging. 


\section{DEVELOPMENT OF THE DE MESTRAL PROJECT, SPRING 2015}

In 2015, the Macro journaling exercise was expanded to a weekly graded class assignment. Each student was tasked with finding an element of a local organism, to photograph it up close or otherwise, search for literature on the specific functional biological phenomenon and to analyze and reflect on ways they might translate the phenomenon into a potential design that solves a functional problem (Fig. 1).

Part of the activity relied again on taking magnified photographs of what they found. Smart phone macro lenses such as Macronaut were further developed by the author for the class using sourced plastic lenses fitted inside of a $3 \mathrm{~d}$ printed plastic frame. These worked with a broader majority of students' phones (iPhone 4-6 with or without cases) (Fig. 2). Another purchased design was used to accommodate students with Samsung Galaxy phones and other models.

Macronaut was optimized in 2015 with roughly $10 \times$ magnification. This magnification created the best balance of making photographed objects intelligible but with enough new otherwise invisible detail to be surprising and intriguing to the students. Overall, students

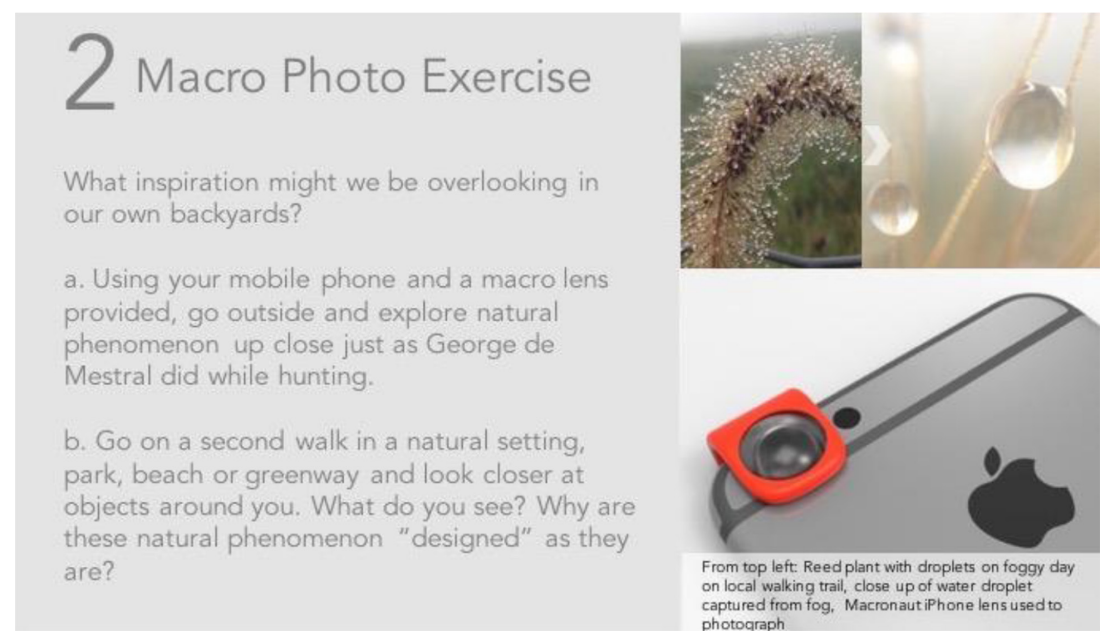

Figure 1: Journal instructions.

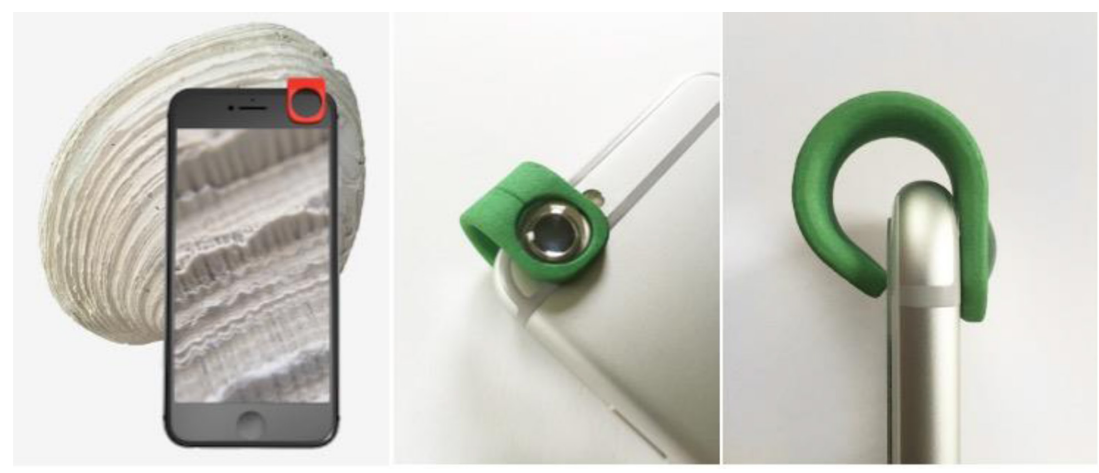

Figure 2: Macronaut lens in use and on student phone. 


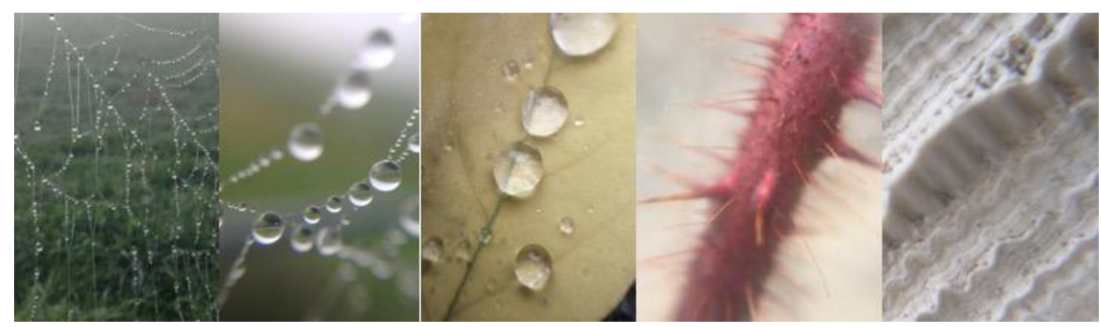

Figure 3: Pictures taken with macronaut: spider web with water, magnified, tulip tree leaf, trichomes \& clam shell.

often found the pictures fascinating and noticed a new phenomenon that sparked creative connections (Fig. 3). The images were also inspiring from an artistic point of view and many were interested in sharing the pictures on social media services like Instagram. An exhibition was held from May to June 2016 in the Moss Arts Center in Blacksburg, Virginia to showcase the students' photography from the class.

Students were given formal templates to follow for their journaling to keep consistent appearance and content. Each week class would begin by sharing out journal progress. Students would pin up their journal entries and describe the connection between a biological artifact they had found and a potentially meaningful solution. Solutions could be visualized and written about, and basic visualization sketching techniques were covered to help every student confidently express their ideas. Some examples included spider webs, leaves, trichomes, lichen, and many other things. Interestingly, over the duration of the class, patterns emerged in the biological phenomenon that drove the journal entries. Many of these phenomena would later serve as the basis for novel design concepts and now funded research topics. For example, many generated ideas centered around water management (hydrophobicity), pest deterrents (Trichomes) and potential other avenues of adhesion, both temporary (English Ivy, Kudzu and Poison Ivy), and permanent (Clam shells). Not always did students find good examples every week. But when stuck, we encouraged students to search for extreme or even annoying biological phenomenon that they could draw from- since we are situated in the southeast USA, vines that stubbornly attach to buildings and trees, were a popular topic. Not every week would we discuss each entry so as to leave time to pursue the team project. This year, however, a few journal entries became the basis for the term projects.

Hydrophobicity became a popular topic in the journals because students could relate to the problems of wetting your pants on rain-drenched a bike seat, having your book or laptop get wet in your back pack or having a leak in the roof from rain or ice. Ultimately, a student

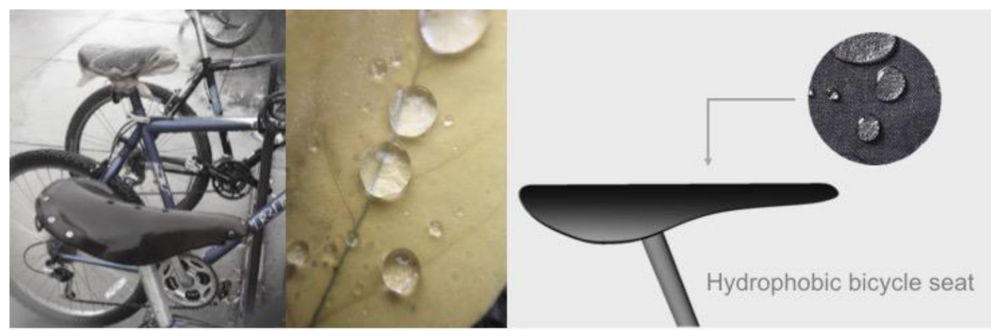

Figures 4 and 5: Wet bicycle seats $>$ Biological Influence $>$ Seat Concept. 
developed the notion of a bike seat surface that was engraved with a super hydrophobic surface akin to a Lotus leaves and Pitcher plants. The principle of hydrophobicity, however, was discovered from a tulip leaf found in their yard (Fig. 4.)

\section{INITIAL OUTCOMES}

The journaling exercise proved successful again given results from an assessment survey completed at the end of the class. Generally, the class praised the use of macro journaling for the following benefits:

1. It helped develop students cultivate their power of observation, no matter what discipline they came from; Macro photography not only revealed a world of detail and function that was otherwise invisible, it also created a mindset of curiosity: looking closer and asking 'why' when looking at nature's design.

2. It fostered an introductory opportunity to build creative confidence, namely share design ideas and provide criticism without creating a sense of discipline specific insecurity (I'm a biologist and can't draw or I am an engineer, I am not creative, or I am a designer I am not technical) [15].

3. Promoted interest and engagement in the promise and practice of BID.

\subsection{Further opportunities for funded research}

Following the class, two projects have continued into early stage funded research projects. Studying the fog drip principles of trees like White Pine and Sequoia Sempervirens, specifically the pine needle geometry and materiality has led to a funded investigation of using linear geometries instead of screen mesh to improve water yield in Fog Capture devices. In addition, studying the corrugated layering of some clam shells has led to the investigation of corrugating layers in FDM 3d printing to increase lateral strength (Fig. 5).

\section{ONGOING EXPANSION THE DE MESTRAL PROJECT}

Additional feedback from the de Mestral project suggested that additional journaling activities could be added to the Macro photography exercise to expand the reach of inspiration opportunities for the journal. The first suggestion was to not limit the photography to $10 \times$ scale. This would allow students to take pictures of phenomenon at full scale as well, which

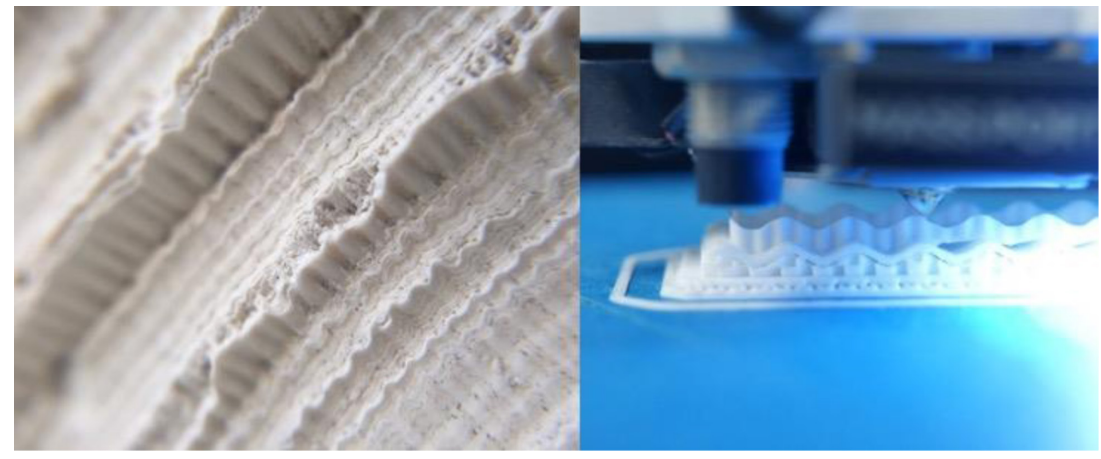

Figure 5: Corrugated clam shell and corrugated 3d print. 
yielded results too. Conversely, using photography at a much greater magnification was requested, including nearer to $400 \times$ which can yield images of butterfly wing scales etc. Others even requested using Scanning Electron Microscopes, of which there are many on the Virginia Tech campus.

Additional student feedback suggested that including new exercises that would investigate species with extreme, superhuman abilities, similar to those found in the warm up exercise at the beginning of the term would be desirable. These "superheroes of nature" provided tremendous fodder for inquiry and inspiration, with documented examples from the past, such as Robert Full's well known work with Geckos and their climbing ability [16]. Some students, when stuck finding exciting models for their journals ended up exploring such extreme abilities and adaptations with meaningful results. One student, for instance, examined the Alpine Ibex' feet which have suction cupped shaped hooves to help them grip to steep, rocky, mountainside faces. This specific example prompted ideas for potential hiking shoes that would enable humans, perhaps rescue teams to grip rocky steep surfaces in a comparable manner. Given that organisms ranging from Geckos, Thorny Devil Lizards, Fireflies, Cacti and so many others have provided extensive stimulus for scientific BID research in the past, adding this exercise to the journal as an option for Spring 2017 would be fitting and valuable.

\section{CONCLUSIONS}

After the successful introduction of the de Mestral project on the Integrating Biology, Engineering and Design seminar, the project was presented at the Virginia Science Festival conference at Virginia Tech in 2015 where high school level educators from the USA and Europe expressed interest in deploying the de Mestral project in their classrooms. Currently, as of May 2016, the journaling exercise is being trialed at the Silkeborg, Denmark Gymnasium, the largest secondary school in the country. Students at this age level, just as their University level counterparts, generally have smart phones with which they can perform the activity. Unfortunately, for intellectual property reasons, the de Mestral project could not be trialed in secondary school classrooms in the USA under the efforts of the Virginia STEM initiative. While the unit cost for the Macronaut is very low, they could not be distributed widely in schools without infringing on a US utility patent held by the makers of a significantly costlier device (Olloclip).

\subsection{Additional applications}

Apart from use in the Integrating Biology, Engineering and Design seminar, the Macronaut lens is also scheduled to be used in other STEM field classes, including Introduction to Biology, Entomology and Ornithology. Mainly the tool will be used to help reveal smaller details of insects and birds but it will also surely contribute to increasing interest in these fields. Part of their use will also be to ask the question: how might natural phenomenon that are being studied be applied to a practical design application?

Overall, the use of these devices in the broader context of BID journaling shows promise for increasing interest in STEM fields and participation in BID. As tools like these continue to be adopted in the University environment this will surely support advancing inquiry into the unique relevance of biology in design while helping ensure BID will increasingly contribute to innovation in social and economic impact.

This research was generously funded by the 4VA Research Program and the Institute for Creativity Arts and Technology at Virginia Tech. 


\section{REFERENCES}

[1] Whitefoot, K.S. \& Olson, S., Making Value: Integrating Manufacturing, Design, and Innovation to Thrive in the Changing Global Economy, The National Academies Press: Washington and DC, 2012.

[2] Kelly, D., Xie, H., Nord, C.W., Jenkins, F., Chan, J.Y. \& Kastberg, D., Performance of U.S. 15-Year-Old Students in Mathematics, Science, and Reading Literacy in an International Context: First Look at PISA 2012, National Center for Education Statistics: Washington and DC, 2013.

[3] US Department of State, 2016, available at: http://www.state.gov/e/oes/stc/stem/index. htm.

[4] National Research Council. Convergence: facilitating transdisciplinary integration of life sciences, physical sciences, engineering, and beyond. Committee on Key Challenge Areas for Convergence and Health. Board on Life Sciences, Division on Earth and Life Studies, The National Academies Press: Washington and DC, 2014.

[5] Wyss Institute for Biologically Inspired Engineering, 2016, available at: http://wyss. harvard.edu/viewpage/537/.

[6] PureBond Hardwood Plywood, available at: http://purebondplywood.com/about/thepurebond-story/.

[7] Fermanian Business \& Economic Institute, Bioinspiration: An Economic Progress Report, 2013, [Online], available at: http://www.pointloma.edu/sites/default/files/filemanager/Fermanian_Business_Economic_Institute/Economic_Reports/BioReport13. FINAL.sm.pdf.

[8] National Research Council. A New Biology for the 21st Century, National Academies Press: Washington, 2009, available at: http://www.nap.edu/catalog.php?record_ $\mathrm{id}=12764$.

[9] Vincent, J.F., Bogatyreva, O.A., Bogatyrev, N.R., Bowyer, A. \& Pahl, A., Biomimetics: its practice and theory. Journal of the Royal Society Interface, 3(9), pp. 471-482, 2006. http://dx.doi.org/10.1098/rsif.2006.0127

[10] Nagel, J., Kennedy, B. \& Buikema, A., Integrating biology, engineering and design for sustainable innovation. In Conference Proceedings: International Stem Education Conference of the IEEE, IEEE: Princeton, 2015.

[11] Center for Biologically Inspired Design, Georgia Institute of Technology, available at: http://www.cbid.gatech.edu/.

[12] The Biomimicry Center, Arizona State University, available at: http://biomimicry.asu. edu/.

[13] Yen, J., Weissburg, M., Helms, M. \& Goel, A., Biologically inspired design: a tool for interdisciplinary education. Biomimietics: Nature-Based Innovation, ed. Y. Bar-Cohen, Taylor \& Francis, pp. 331-360, 2011.

[14] Biomimicry 3.8 Institute, AskNature - The Biomimicry Webportal, Available at: http:// www.asknature.org/, (accessed 20 May 2016).

[15] Kelley, T. \& Kelley, D., Creative Confidence, Crown Publishing: New York, 2013.

[16] Autumn, K., Sitti, M., Liang, Y.A., Peattie, A.M., Hansen, W.R., Sponberg, S., Kenny, T.W., Fearing, R., Israelachvili, J.N. \& Full, R.J., Evidence for van der Waals adhesion in gecko setae. Proceedings of the National Academy of Science, 99(19), pp. 1225212256, 2002.

http://dx.doi.org/10.1073/pnas.192252799 